\title{
EL CONTENCIOSO URBANÍSTICO Y SU NECESARIA REFORMA
}

\author{
TOMÁS-RAMÓN FERNÁNDEZ1 \\ Universidad Complutense de Madrid
}

Cómo citar/Citation

Fernández, T.-R. (2017).

El contencioso urbanístico y su necesaria reforma. Revista de Administración Pública, 203, 137-162. doi: https://doi.org/10.18042/cepc/rap.203.04

\section{Resumen}

Se analizan las reformas realizadas en Francia para dar respuesta a los problemas que la conflictividad propia del urbanismo proyecta sobre el proceso contenciosoadministrativo (recursos abusivos, sentencias de demolición, etc.), así como la situación en España, que es muy semejante, y se sugieren algunos cambios en la jurisprudencia y ciertas reformas legales.

\section{Palabras clave}

Urbanismo; proceso contencioso-administrativo; recursos abusivos; demolición; jurisprudencia.

\section{Abstract}

In this article we analyze the problems provoked in France and Spain by the abusive actions in the field of urban planing, the reforms introduced in Francia and the necesary changes in the spanish rules and jurisprudence about these problems.

\section{Keywords}

Urban planning; contentious-administrative process; abusive actions; demolition; jurisprudence.

\footnotetext{
1 Catedrático emérito.
} 


\section{SUMARIO}

I. LA PRESIÓN QUE EJERCE SOBRE EL PROCESO CONTENCIOSO-ADMINISTRATIVO LA EXTRAORDINARIA CONFLICTIVIDAD QUE GENERA LA ACTIVIDAD URBANÍSTICA: LOS CASOS FRANCÉS Y ESPAÑOL. II. BREVE REPASO A LAS REFORMAS INTRODUCIDAS EN EL CONTENCIOSO FRANCÉS DEL URBANISMO. III. $\dot{2}$ ES NECESARIO REFORMAR NUESTRO PROCESO CONTENCIOSO-ADMINISTRATIVO EN MATERIA DE URBANISMO?: 1. Reformas legales y/o rectificaciones jurisprudenciales. 2. La hipervaloración de las formas. 3. Quod ab initio nullum est nullum effectum producit. 4. Rectificaciones necesarias de la jurisprudencia al uso. 5. Reformas legales que sería conveniente introducir en el proceso contencioso del urbanismo. IV. REFLEXIÓN FINAL.

\section{LA PRESIÓN QUE EJERCE SOBRE EL PROCESO CONTENCIOSO- ADMINISTRATIVO LA EXTRAORDINARIA CONFLICTIVIDAD QUE GENERA LA ACTIVIDAD URBANÍSTICA: LOS CASOS FRANCÉS Y ESPAÑOL}

Hace ya tres ańos, comentando el gravísimo problema planteado por la ejecución (o la inejecución en muchos casos) de las sentencias firmes que comportan la demolición de edificios, me hice eco del informe emitido por el grupo de trabajo creado por la ministra francesa de Igualdad de los Territorios y de la Vivienda, Cécile Duflot, y presidido por Daniel Labetoulle, expresidente de la Sección de lo Contencioso del Conseil d'Etat, que entonces acababa de hacerse público con el título Construction et Droit au recours: pour un meilleur équilibre ${ }^{2}$.

2 Véase T. R. Fernández (2013), «Proceso contencioso-administrativo y urbanismo: semejanzas y diferencias de los casos francés y español», Revista de Urbanismo y Edificación, 29, págs. 77-95; y T. R. Fernández (20 I 4), «Long cours. Mélanges en l’honneur de Pierre Bon», Dalloz, págs. 851-868. 
Me pareció importante, en efecto, dar cuenta de dicho informe y de sus concretas propuestas de modificaciones legales porque, a pesar de la diferente forma en la que se proyecta sobre el proceso contencioso-administrativo la notable conflictividad que genera la actividad urbanística en Francia y en España, las causas últimas son las mismas allí y aquí. Como el Informe Labetoulle advierte con acierto en su introducción, «lo que está en causa es, primero y ante todo, el fondo del Derecho Urbanístico y Ambiental» ${ }^{3}$.

En ambos países tenemos que atender, en efecto, a una multiplicación de normas de referencia, "tanto nacionales, como locales», dice el informe, lo que es particularmente cierto en nuestro caso, no en vano contamos con dieciocho legisladores en materia ambiental y urbanística, situación esta ya de por sí compleja, que se agrava, ciertamente, "por los cambios incesantes de las que son objeto, así como las propias disposiciones legislativas y reglamentarias» que dan soporte a la normativa contenida en los distintos tipos de planes, lo que «fragiliza los proyectos y les hace vulnerables a las acciones contenciosas emprendidas por recurrentes avisados».

A todo esto se ańade el efecto conjugado de los derechos nacional y europeo, que hacen «más pesados, más largos y más difíciles de maîtriser por los promotores de los proyectos» los procedimientos previos a la entrega de una autorización de urbanismo, como ilustra, «de manera paroxística", la introducción de un régimen de examen caso por caso de que esos proyectos sean precedidos de un estudio de impacto sobre el medio ambiente y la salud humana. De esto también tenemos nosotros abundante experiencia.

En Francia y en España se necesitan también varios años para agotar las vías de recurso contra una autorización de urbanismo, vías que «a veces son subvertidas por fines que les son extraños y que pueden incluso llegar, en ciertos casos, a parecerse a una forma de chantaje».

Hay, desde luego, diferencias en la forma de proyectarse sobre el proceso estos fenómenos, sobre todo porque en Francia la interposición de recursos contra los permisos de construcción y las demás autorizaciones urbanísticas basta, en la generalidad de los casos, para paralizar la ejecución de las obras, no porque el recurso tenga carácter suspensivo, ni porque el acto recurrido no sea ejecutorio, sino porque los financiadores, ya sean los bancos o los propios adquirentes, rehúsan comprometerse con un proyecto en tanto este no esté libre de todo contencioso, a pesar de los mecanismos de seguro que han comenzado a utilizarse, reservas que comparten los propios notarios.

3 Esta y las demás expresiones y frases entrecomilladas que la siguen en el texto pertenecen al informe. 
Entre nosotros, en cambio, sucede exactamente lo contrario, como es bien sabido. La impugnación de un plan de urbanismo, de un instrumento de gestión o de una licencia de construcción provoca una fuite en avant, una aceleración deliberada de los procesos iniciados antes de ella, con el deseo y la esperanza de que los hechos consumados operen a favor del afectado, lo que conduce a un callejón sin salida cuando la sentencia que pone fin al proceso trabado anula el plan o el acto recurrido.

En uno y otro caso el precio es la inseguridad, una importante e inaceptable inseguridad, a la que en Francia han intentado dar respuesta, lo que contrasta con la pasividad que domina entre nosotros.

En efecto, las propuestas formuladas en abril de 2013 por el Informe Labetoulle pasaron a ser poco después derecho positivo con la publicación de la ordenanza 2013/638, de 18 de julio, ratificada y completada por el Decreto 2013/879, de 1 de octubre, que incorporó al Código de Urbanismo la mayoría de ellas. La Ley, llamada ALUR, de 24 de marzo de 2014, para el acceso a la vivienda y un urbanismo renovado y la Ley 2015/990, de 6 de agosto, para el crecimiento, la actividad y la igualdad de oportunidades económicas ${ }^{4}$, han hecho el resto, lo que contribuye a dibujar en el país vecino un nuevo escenario para el proceso contencioso-administrativo, en el que el juez ha pasado a ocupar una posición de protagonista, como acaba de resaltar en el último número de la Revue de Droit Public un magistrado del Tribunal Administrativo de Apelación de Nantes, H. Delesalle, en un trabajo cuyo título no podrá menos de excitar la curiosidad de nuestros jueces y magistrados que han ejercido o ejercen la jurisdicción en materia de urbanismo: La place nouvelle du juge administratif dans le droit de l'urbanisme ${ }^{5}$.

El Gobierno, el legislador y los jueces administrativos han dado, de consuno, en Francia una respuesta rápida y pienso que eficaz también a los graves problemas que plantea la extraordinaria y muchas veces insana conflictividad que la actividad urbanística genera, lo que constituye, sin duda, un ejemplo y un estímulo para nosotros y justifica, cuando menos en lo que a mí concierne, realizar un nuevo intento y llamar otra vez la atención sobre el asunto, así como sobre la necesidad de realizar una reflexión general al respecto, ya que no tuvo ningún eco, como es notorio, el que hice en 2013 con motivo de la aparición del Informe Labetoulle.

\footnotetext{
4 Como puede verse, en Francia es también usual apelar a las leyes coyunturales para introducir todo tipo de reformas tenga o no que ver con la coyuntura económica.

5 Véase H. Delesalle (2016), «La place nouvelle du juge administratif dans le droit de l'urbanisme», Revue de Droit Public, 6, pág. 1759.
} 


\section{BREVE REPASO A LAS REFORMAS INTRODUCIDAS EN EL CONTENCIOSO FRANCÉS DEL URBANISMO}

Como en su momento señalé, el Informe Labetoulle propuso siete medidas muy concretas: clarificar las reglas del interés legitimador, introducir un procedimiento de cristalización de los motivos de impugnación, organizar un mecanismo de regularización a iniciativa del juez, en el curso del procedimiento, permitir al demandado formular reconvención para exigir al recurrente una indemnización por los daños y perjuicios que haya podido causarle la interposición del recurso, encuadrar el régimen de transacciones mediante las cuales se pone fin al proceso, recentrar la acción de demolición sobre su objeto primero y dar a los tribunales de apelación la competencia para conocer en primera y única instancia determinados proyectos de construcción de viviendas.

Voy a repasar ahora rápidamente aquellas que pueden tener más interés para nosotros para prestar luego mayor atención a la que, a mi juicio, es la estrella: la regularización en el curso del proceso de los vicios que pudieran dar lugar a la anulación de los permisos de construcción y de los planes de urbanismo que son objeto de dicho proceso.

Una parte de las medidas propuestas por el Informe Labetoulle e incorporadas luego al Código de Urbanismo por la ordenanza de 18 de julio de 2013 responde directamente al propósito de cerrar el paso a los recursos abusivos o malintencionados, a los que Labetoulle no duda en llamar "crapulosos»" .

Este es el caso de las restricciones temporales y materiales relativas al interés legitimador. A partir de la ordenanza citada es necesario que el interés invocado resulte de circunstancias anteriores a la publicación en el tablón de anuncios de la alcaldía de la solicitud de peticionario de la autorización. Si se trata de asociaciones, se exige igualmente que el depósito de sus estatutos en la prefectura haya tenido lugar antes también de dicha publicación, lo que, ciertamente, reduce las posibilidades de los recurrentes oportunistas.

En esa misma dirección opera la exigencia de dejar bien establecido el impacto que el proyecto autorizado pueda tener sobre la situación del recurrente, esto es, si dicho proyecto puede afectar directamente a las condiciones de ocupación, de utilización o de goce de sus bienes?

Al mismo propósito disuasorio de los recursos abusivos responde el derecho que el nuevo art. L-600-7 del Código de Urbanismo ha venido a reconocer al titular de un permiso de construcción o de urbanización de formular

Ibid.: 1776.

Ibid.: 1764. 
reconvención en el seno del propio recurso por excés de pouvoir interpuesto contra dichos permisos, solicitando del juez la condena del recurrente al pago de los dańos y perjuicios que hayan podido resultar para él del recurso en cuestión.

La medida es, ciertamente, llamativa, dado el carácter tradicionalmente objetivo del excés de pouvoir, cuya función institucional se limita a la verificación de la legalidad del acto o de la disposición recurrida. Su utilidad es, en principio, bien notoria, ya que viene a ahorrar el siempre posible, aunque inhabitual, proceso ulterior ante la jurisdicción civil que el demandado podría promover en calidad de actor contra el recurrente abusivo o malicioso, lo que, sin duda, constituye un progreso, aunque, como H. Delesalle precisa, la jurisprudencia hasta ahora producida sea todavía balbuciente ${ }^{8}$ por la dificultad de precisar cuándo puede considerarse excedido lo que es propio de la defensa de los legítimos intereses del recurrente.

En estrecha relación con lo anterior se ha impuesto la obligación de registrar en la Administración tributaria toda transacción en virtud de la cual quien ha demandado la anulación de un permiso de construir o de urbanizar se compromete a desistir de su recurso a cambio de un pago en metálico o en especie, so pena de considerar que dicha transacción carece de causa y queda sujeta al eventual ejercicio de un acción de repetición en el plazo de cinco años a contar del último pago realizado.

Y, en fin, para desincentivar la interposición de recursos abusivos el Informe Labetoulle propuso limitar la acción de demolición de las construcciones levantadas al amparo de un permiso anulado a las situadas en zonas sensibles, naturales o no, esto es, espacios naturales notables, banda litoral de cien metros, reservas naturales, zonas Natura 2000, perímetros de prevención de riesgos, entorno de monumentos históricos, etc., propuesta que hizo suya la Ley de 6 de agosto de 2015 incorporándola al art. L. 480-13 del Código de Urbanismo.

Aunque todas las medidas hasta aquí expuestas tienen un indudable interés, las más importantes son las que responden al principio de regularización que la Ley, llamada ENEL, de 13 de julio de 2006, introdujo para los permisos de construcción y que la Ley, llamada ALUR, de 24 de marzo de 2014, extendió a los documentos de urbanismo?.

De lo que se trata es de limitar los efectos devastadores de las excepciones de ilegalidad perpetuas y de evitar la contaminación de los actos atacados por

\footnotetext{
Ibid: 1766.
}

9 Esto es, a los planes locales de urbanismo, a los esquemas de coherencia territorial y cartas municipales. 
la ilegalidad de otros actos anteriores y, muy particularmente, de los planes locales de urbanismo, así como de evitar que se anulen proyectos, en particular los de especial amplitud o importancia, por el incumplimiento de reglas finalmente accesorias y cómodamente corregibles, lo que $\mathrm{H}$. Delesalle no duda en calificar de aberrante ${ }^{10}$.

El Informe Labetoulle dio un impulso decisivo a esta idea, que alguna jurisprudencia había explorado con anterioridad, al formular dos propuestas concretas, que ahora recogen la nueva redacción del art. L. 650-5 y el nuevo art. L. 600-5-1 del Código de Urbanismo.

De acuerdo con dichos preceptos, si el juez administrativo estima que un vicio que haya podido detectar no afecta más que a una parte del proyecto y puede ser regularizado por un permiso modificativo, puede limitar el alcance de la anulación a la concreta parte afectada e, incluso, fijar un plazo dentro del cual el titular del permiso impugnado podrá solicitar la regularización.

Puede también en estos casos dejar en suspenso el procedimiento hasta la expiración del plazo que fije para proceder a la regularización ${ }^{11}$.

La Ley ALUR de 24 de marzo de 2014 ha extendido este doble sistema de anulaciones parciales y de suspensión del plazo para resolver en espera de un permiso modificado a los documentos de urbanismo y a los esquemas de coherencia territorial, aunque de forma un poco más compleja y restrictiva.

En concreto, cuando se trata de documentos la suspensión solo puede ser acordada por el juez si el vicio de fondo del que, en principio, adolezca el plan impugnado es benigno y puede ser regularizado mediante un simple procedimiento de modificación o si se trata de un vicio de legalidad externa que se haya producido en una fase avanzada del proceso de elaboración ${ }^{12}$.

En cualquier caso, este tipo de decisiones pueden ser adoptadas de oficio por el juez, aunque no medie petición de parte. La Ley no le obliga, por supuesto, a adoptarlas, pero, como advierte H. Delesalle, sí existe, en cambio, una cierta obligación moral en este sentido que se le impone para dar pleno efecto a la voluntad del legislador, lo que ha facilitado que la utilización de este tipo de medidas haya entrado ya en los hábitos procesales ${ }^{13}$.

El juez administrativo ha adquirido así un papel nuevo en el proceso, un papel activo, muy alejado de esa posición de simple espectador que oye a las partes, estudia el asunto y pronuncia al final su veredicto desentendiéndose, sea cual sea este, de sus posibles consecuencias. Lo que se espera de él ahora es

\footnotetext{
10 Ibid. : 1772.

11 Ibid.: 1770.

12 Ibid.: 1771.

13 Ibid.
} 
que sea beligerante en pro de la regularización de los actos impugnados cuando esta sea posible, que defienda, ciertamente la legalidad, pero que no olvide el factor seguridad, que es también imprescindible para el funcionamiento regular de la vida social.

Las reformas expuestas llevan así a término una línea evolutiva que arranca de la Ley 112, de 9 de febrero de 1994, que obligó al juez administrativo a indicar el conjunto de motivos susceptibles de fundar la anulación de los actos de urbanismo que él pronuncia, lo que facilita la regularización del acto anulado. El juez, dice H. Delesalle, se convierte así en "consejero» de la Administración con el fin de orientarla y guiarla sobre lo que puede ser o no retomado en un nuevo acto posterior y de evitar de este modo la repetición de un nuevo proceso ${ }^{14}$.

Resta ya solamente indicar que la puesta en juego de este conjunto de reformas parece haber tenido una incidencia positiva. La disminución del número de recursos, que se había iniciado en $2012(-5 \%)$ y $2013(-2 \%)$ se ha acelerado espectacularmente, al parecer, en 2014 (-10\%), tendencia confirmada en 2015 con un nuevo descenso del $4 \%$.

El contencioso de los permisos de construcción, en concreto, no ha dejado de disminuir desde los 4166 en 2012 a los 3500 aproximadamente de 2015, un $16 \%$ menos, por lo tanto. Es difícil, dice H. Delesalle, ver en esta disminución el simple efecto del azar o de la crisis ${ }^{15}$.

Parece también, según este autor, que el número de anulaciones totales ha disminuido, aunque en este caso hay un vacío estadístico. La experiencia, aunque corta, resulta en todo caso estimulante ${ }^{16}$. Hay, pues, material abundante para la reflexión sobre nuestra propia realidad.

\section{III. ¿̇ES NECESARIO REFORMAR NUESTRO PROCESO CONTENCIOSO-ADMINISTRATIVO EN MATERIA DE URBANISMO?}

\section{REFORMAS LEGALES Y/O RECTIFICACIONES JURISPRUDENCIALES}

La pregunta que acabo de formular parece dar por supuesto que, de ser positiva la respuesta, esta tendría que venir del legislador. Tendría que ser, además, del legislador estatal, ya que es a él a quien corresponde en exclusiva la legislación procesal.

$14 \quad$ Ibid.: 1779.

15 Ibid.: 1773.

16 Ibid.: 1774. 
Sin embargo, antes de reclamar la intervención del legislador me parece necesario apelar a una instancia más cercana, la jurisprudencia, que es la responsable, junto con la doctrina, de la evolución de nuestro derecho administrativo en el último medio siglo, que es, más o menos, el tiempo transcurrido desde el acceso al Tribunal Supremo de las primeras promociones de la escala de magistrados especialistas creada por la benemérita Ley de la Jurisdicción de 27 de diciembre de 1956, punto de arranque de lo que ha sido el diálogo fructífero que nos ha traído hasta aquí.

La Sección $5^{a}$ de la Sala $3^{a}$ del Tribunal Supremo, desde que fue presidida por J. Delgado Barrio, ha desarrollado una labor importantísima en el campo del urbanismo. Hay, en cambio, aspectos de su doctrina que adolecen de una extraordinaria rigidez que contribuye a agravar notablemente los problemas que generan de por sí la complejidad del ordenamiento urbanístico y la forma en que se comportan los distintos actores que operan en el escenario que este preside.

Dos son los aspectos en que se manifiesta la rigidez a la que me refiero: la hipervaloración de los vicios de procedimiento y la maximalización de los efectos de la nulidad que deriva de la apreciación de aquellos. A ambos me referiré brevemente a continuación.

\section{LA HIPERVALORACIÓN DE LAS FORMAS}

Es indudable la especial importancia que tiene el procedimiento de elaboración de los planes urbanísticos, lo que justifica, sin duda, el mayor rigor con el que debe valorarse su eventual infracción. La Sentencia de 9 de julio de 1991, de la que fue ponente J. Delgado Barrio, lo explicó muy bien, por lo que me parece oportuno recordar sus términos:

El planeamiento es una decisión capital que condiciona el futuro desarrollo de la vida de los ciudadanos [...] En otro sentido, integra una intensa regulación de la propiedad privada [...] De aquí deriva ya la transcendental importancia del procedimiento de elaboración de los planes, precisamente para asegurar su legalidad, acierto y oportunidad —art. 129 de la Ley de Procedimiento Administrativo- . Entre sus trámites destacan aquellos que tiendan a lograr la participación ciudadana, [que] hoy resulta seriamente reforzada por virtud de lo establecido en los arts. 9.2 y 105.a) de la Norma Fundamental: la intervención de los ciudadanos contribuye a dotar de legitimidad democrática a los planes.

A todo ello se une «el carácter ampliamente discrecional del planeamiento", por lo que:

[...] resulta claro que hay un núcleo último de oportunidad, allí donde son posibles varias soluciones igualmente justas, en el que no cabe sustituir la decisión 
administrativa por una decisión judicial. Así las cosas, existen alegaciones de rigurosa y pura oportunidad que hechas ante la Administración en un trámite de información pública pueden dar lugar a que aquélla modifique su criterio, en tanto que alegadas en la vía jurisdiccional pueden resultar inoperantes.

En otras palabras, para valorar en su justa medida los vicios de procedimiento hay que tener muy presente lo que restan, lo que se pierde con ellos, lo que pierde, en definitiva, la decisión final del procedimiento de que se trate. Esto es exactamente lo que dijo hace ya más de un siglo la Sentencia del Tribunal Supremo de 29 de enero de 1915, que me gusta recordar siempre que se presenta la ocasión:

[...] cuando las Leyes y Reglamentos no declaran expresamente nulos los actos contrarios a sus preceptos, la apreciación de si el quebrantamiento cometido entraña nulidad depende de la importancia que revista, de las derivaciones que motive, de la situación o posición de los interesados en el expediente y, en fin, de cuantas circunstancias concurran, que deberán apreciarse en su verdadero significado $y$ alcance para invalidar las consecuencias de los actos o para mantenerlos.

Hay, pues, que tener en cuenta «sobre todo, lo que hubiera podido variar el acto administrativo origen del recurso en caso de observarse el trámite omitido", en palabras de la Sentencia de 6 de noviembre de 1963. ¡Es una pena que habiendo profundizado tanto en otros puntos hayamos dejado en el olvido estas viejas y sabias palabras!

¿Por qué digo esto? Porque estoy harto de ver cómo caen planes generales y normas subsidiarias del planeamiento de grandes ciudades o de pequeńas poblaciones porque no se emitió tal o cual informe, porque no se justificó suficientemente esta o aquella determinación, porque la evaluación del impacto ambiental se hizo de acuerdo con la legislación autonómica o con la legislación estatal, porque no se respondió a todas las alegaciones formuladas en el trámite de información pública o, en fin, iporque se omitió el informe de impacto de género!

En la mayoría de los casos brilla por su ausencia una valoración de lo que con el vicio apreciado se ha perdido, de lo que hubiera podido variar la decisión final si dicho vicio no se hubiera cometido.

Tengo en la mano un buen ejemplo de lo que digo: la Sentencia del Tribunal Supremo de 22 de septiembre de 2015, que, estimando el recurso de casación interpuesto contra la de la Sala de Málaga del Tribunal Superior de Justicia de Andalucía de 23 de marzo de 2012, ha anulado el Decreto de 18 de julio de 2006 que aprobó el Plan de Ordenación del Territorio de la Costa del Sol Occidental de la provincia de Málaga y declarado nulo de pleno derecho (sic) el citado plan. 
Los vicios procedimentales imputados al decreto aprobatorio del plan en cuestión fueron dos: en primer lugar, el de no haber contestado (o, por lo menos, no haberlo hecho de manera suficientemente explícita, porque alguna respuesta si se dio) las alegaciones formuladas por el recurrente en el trámite de información pública y, en segundo lugar, por haber omitido el informe de impacto de género exigido con carácter general para toda clase de reglamentos por la Ley andaluza de 29 de diciembre de 2003 y por la propia Ley del Gobierno 50/1997, a raíz de su modificación por la Ley 30/2003, de 13 de octubre, que sería en todo caso aplicable supletoria o analógicamente.

Me referiré aquí solamente a este último, que es particularmente... estridente, tal y como la Sentencia del Tribunal Supremo lo valora. Comienza esta diciendo en su fundamento jurídico sexto que «la entidad mercantil demandante no ha expresado a lo largo del pleito la incidencia que las determinaciones del Plan de ordenación territorial combatido puedan tener para esa igualdad propugnada entre hombres y mujeres».

Pese a ello no duda en afirmar en términos tajantes que:

[...] la Sala no comparte la tesis de la Administración autonómica demandada relativa a que, como no existen en dicho Plan determinaciones con incidencia en materia de género, resultaba innecesario el informe de evaluación de impacto de género, ya que sería en el informe a emitir donde se debería explicar tal circunstancia, lo que además podría ser objeto de controversia, que no se ha podido suscitar a falta del preceptivo informe atendido el carácter reglamentario o de disposición de carácter general del Plan de Ordenación impugnado, lo que implica... la nulidad radical de la norma recurrida conforme a lo dispuesto conocidamente en los arts. 62.2 de la Ley 30/1992, de Régimen Jurídico de las Administraciones Públicas y del Procedimiento Administrativo, 68.1.b), 70.2, 71.1.a) y 72.2 de la Ley de la Jurisdicción Contenciosa-Administrativa, como, además, ha venido a declarar esta Sala del Tribunal-Supremo en supuesto de falta del indicado informe (Sentencias de 16 de abril de 2013 — recurso de casación 647/2011- y 8 de enero de 2014 — recurso de casación 2651/2012).

Los términos en que se planteó el problema no pueden ser más llamativos: el recurrente simplemente denunció la falta del informe de impacto de género sin molestarse lo más mínimo en indicar siquiera la importancia que tal omisión pudiera tener para la defensa y protección de sus legítimos derechos, lo que demuestra que no le afectaba ni poco, ni mucho, ni nada y la Sala se limitó a constatar que la colección de trámites no estaba completa y sin importarle tampoco la incidencia que el trámite omitido pudiera haber tenido en la «legalidad, acierto y oportunidad» del plan impugnado se apresuró a decretar la nulidad radical de este. 
¿Tiene esto algún sentido? ¿Es razonable declarar nulo de pleno derecho en su totalidad un Plan de Ordenación Territorial al cabo de nueve ańos (iii) porque se echa en falta un informe que nadie considera que pueda tener transcendencia alguna por su falta absoluta de relación con el objeto del mismo? Una sentencia reciente del Tribunal Superior de Justicia de Madrid de 19 de abril de 2017 considera que sí lo es porque ha anulado por el mismo motivo el Plan General de Ordenación de Boadilla del Monte apoyándose en una larga y circunstanciosa argumentación.

A mí me parece que no lo tiene en absoluto y que, sin necesidad de pedir ayuda al legislador para que cambie las normas aplicables, nuestro más Alto Tribunal podía haber resuelto el problema de otra manera dando sencillamente a las formas el valor que realmente tienen, que la ley las otorga y que su propia jurisprudencia las ha reconocido también muchas veces ${ }^{17}$.

Pero no voy a discutir esto, porque supongo que es innecesario, ya que el problema de la valoración de los vicios de forma y procedimiento es muy viejo y por ello bien conocido. Lo único que quiero subrayar - y en esto creo que estará conmigo la inmensa mayoría no ya de los juristas, sino simplemente de las personas razonables - es que las cosas no deberían ser así y que, si no es en sede jurisdiccional, en sede parlamentaria alguien tiene que imponer lo que el sentido común reclama a gritos, a saber: que si falta un informe se reclame cuanto antes a quien debe emitirlo para que lo haga en el plazo perentorio que se le conceda al efecto sin esperar a que transcurran nueve largos años, en los que pueden ocurrir muchas cosas, que a posteriori tienen mal arreglo cuando tienen alguno, que no siempre ocurre.

Cualquier cosa antes que declarar nulo de pleno derecho con nueve años de retraso un plan de ordenación por la falta de un informe absolutamente banal. Dejo que hable por mí el magistrado de Nantes H. Delesalle: «[...] parece retrospectivamente aberrante que proyectos, en especial los de importancia, hayan podido ser pura y simplemente anulados por un incumplimiento de reglas finalmente accesorias y cómodamente regularizables» ${ }^{18}$.

\section{QUOD AB INITIO NULLUM EST NULLUM EFFECTUM PRODUCIT}

La hipervaloración de las formas a la que acabo de referirme conduce a la declaración de la nulidad de pleno derecho de los planes de ordenación a los que afecta, de todo el contenido de esos planes normalmente, por mínimo e irrele-

17 Me remito sobre este asunto al reciente libro de J. García Luengo (2016), Las infracciones formales como causa de invalidez del acto administrativo, Madrid: Iustel.

18 Véase H. Delesalle (2016: 1772). 
vante que pudiera ser el trámite omitido, ya que, como acabamos de comprobar, la jurisprudencia no exige al recurrente que precise en qué medida ha podido afectarle dicha omisión y ni acepta que la Administración demandada alegue que éste era innecesario o irrelevante dadas las concretas circunstancias del caso, ni considera tampoco procedente que se compruebe en el curso del proceso si efectivamente lo era. Falta el informe de impacto de género y no hay más que hablar: todas las normas de ordenación de dicho plan son nulas por mucho que parezca evidente que no tienen absolutamente nada que ver con la igualdad entre hombres y mujeres, ya que «sería en el informe a emitir donde se debería explicar tal circunstancia, lo que, además, podría ser objeto de controversia, que no se ha podido suscitar al faltar el preceptivo informe», como afirma solemnemente la Sentencia de 22 de septiembre de 2015, a la que he referido más atrás.

La declaración de nulidad de pleno derecho del Plan de Ordenación del territorio de la Costa del Sol Occidental de 2006 pronunciada por la citada sentencia nueve años después puede no haber producido muchos destrozos, dada la naturaleza de dicho plan, aunque no puede descartarse, por supuesto, que en los nueve ańos transcurridos no se hayan modificado muchos planes generales municipales para ajustarlos, como es preceptivo, a sus determinaciones, con la consiguiente incidencia que esos ajustes hayan podido tener en el tráfico inmobiliario.

Pero, en fin, tratándose de un plan territorial, podemos admitir, al menos a los efectos de la reflexión que aquí propongo, que las consecuencias de la declaración de nulidad no hayan sido graves. Sí lo son, sin embargo, cuando el plan que se declara nulo por un vicio de este tipo es un plan general municipal, porque en este caso es obvio que en los nueve años siguientes a su entrada en vigor se producen inevitablemente muchos actos administrativos en ejecución del mismo, ya sea la aprobación de planes de sectorización o parciales, ya la de instrumentos de gestión, tales como proyectos de reparcelación o de urbanización, etc., por no hacer referencia al otorgamiento de licencias de construcción, a todo lo cual hay que añadir la multitud de negocios jurídicos privados que la aprobación de un nuevo plan general hace surgir, habida cuenta del «parón» del tráfico inmobiliario que el largo proceso de elaboración de estos planes suele suponer.

Pues bien, todo este torrente de actos y negocios jurídicos, públicos y privados, generado por un plan general municipal de ordenación urbana se viene abajo súbitamente cuando ese plan se declara nulo de pleno derecho, porque la jurisprudencia al uso es en este supuesto inflexible: quod ab initio nullum est nullum efectum producit.

Es categórica en este sentido la Sentencia de 28 de septiembre de $2012^{19}$, que retrotrajo la situación urbanística de Madrid al momento anterior a la

19 Realmente son dos sentencias, aunque idénticas. 
aprobación definitiva de su Plan General de Ordenación Urbana de 1997, resucitando así el Plan General de 1985 y obligando, en consecuencia, a recorrer otra vez desde el principio el largo y complicado itinerario que el art. 57 de la Ley del Suelo de la Comunidad de Madrid de 17 de julio de 2001 establece para la aprobación de los planes generales y de sus modificaciones y revisiones para llegar, después de tan fatigoso recorrido, al punto de partida inicial, esto es a la ordenación aprobada en 1997, con el acuerdo del Consejo de Gobierno de 1 de agosto de 2013 por el que se aprobó definitivamente la Revisión Parcial del Plan General de Ordenación Urbana de Madrid de 1985 y Modificación del Plan General de Madrid de 1997, en los ámbitos afectados por la ejecución de las sentencias del Tribunal Superior de Justicia de Madrid de 27 de febrero de 2003 y del Tribunal Supremo de fecha 3 de julio de 2007 y 28 de septiembre de 2012 .

He transcrito intencionadamente el título completo del acuerdo del Consejo de Gobierno de la Comunidad de Madrid de 1 de agosto de 2013, que ha puesto fin a los quince larguísimos años de incertidumbre por los que ha atravesado el urbanismo de la capital, para que el lector no familiarizado con esta historia, que es solo una entre muchas, aunque sus proporciones sean lógicamente mayores por afectar a una población de más de cuatro millones de habitantes, tenga una idea al menos de este tortuoso proceso en el que se han producido una sentencia y un auto del Tribunal Superior de Justicia de Madrid y dos sentencias sucesivas del Tribunal Supremo en los recursos de casación promovidos contra las resoluciones de instancia citadas.

Y todo eso, ¿por qué?, se preguntará más de uno. Pues porque el Tribunal Superior de Justicia de Madrid consideró que no estaba suficientemente justificada la clasificación por el Plan General como suelo urbanizable de veintidós ámbitos de los alrededores de Madrid que el Plan precedente tenía clasificados como suelo no urbanizable de protección. Pero ¿tanto suelo hay en los alrededores de Madrid cuyos recursos naturales o sus valores paisajísticos, históricos, culturales, etc., justifiquen el otorgamiento de esa protección? En absoluto, todo el que haya entrado o salido de Madrid por cualquier carretera entre la de Barcelona y la de Extremadura sabe perfectamente que en esa amplísima sección del círculo no hay absolutamente nada que merezca la pena preservar y que los únicos terrenos de dicho círculo valiosos desde este punto de vista son los que se divisan a ambos lados de la carretera de La Coruña. ¿Por qué entonces tan enfática clasificación como suelo no urbanizable de protección? Pues simplemente porque el Texto Refundido de la Ley del Suelo de 1992, vigente cuando se elabora y aprueba el Plan General de 1997, eliminó la separación en dos párrafos del suelo urbanizable común y del suelo no urbanizable de protección tal y como figuraba en el art. 80 del Texto Refundido precedente de 9 de abril de 1976 y juntó en su art. 12 todo en un solo párrafo, así 
que todo quedó aparentemente en suelo no urbanizable de protección. Parece increíble, pero es así. Ahí está la realidad para comprobarlo.

Dejando esto a un lado, que es ya una simple anécdota, la pregunta que cualquier persona sensata se hace inevitablemente al contemplar estos quince años de incertidumbre - $\mathrm{y}$ para muchos, por supuesto, de angustia- es ¿por qué no se requirió al Ayuntamiento de Madrid una justificación más precisa, si es que la tenía? Eso podía haberse hecho al dar sus primeros pasos el recurso interpuesto contra el Plan General de 1997 y en un mes hubiera podido tenerse una respuesta del Ayuntamiento, que hubiera podido aportar una justificación más convincente o no. En el primer caso, el vicio hubiera quedado subsanado con beneficio para todos y, en primer término, para el propio interés general; en el segundo, se hubiera perdido ciertamente un mes, que realmente no es nada tal como están las cosas, pero el recurrente, que denunció el vicio, y el Tribunal, que finalmente declaró la nulidad del Plan, se hubieran cargado de razón. En ambos casos se hubiera evitado el penoso y aun patético viacrucis de quince años, alimentado y explotado por profesionales de la acción pública que disparaban contra todo lo que se movía con todas las posibilidades de derribarlo porque todo, absolutamente todo, lo que trae causa de un plan declarado nulo es también nulo.

Esa es la tesis que luce en la Sentencia de 28 de septiembre de 2012 y en otras muchas anteriores y posteriores a ella ${ }^{20}$. Lo que se discutía según precisa su fundamento primero cuarto, era:

[...] si es subsanable o no esa falta de justificación determinante de la nulidad del plan, de manera que pueda corregirse ahora tal omisión, elaborando la correspondiente memoria o complemento de memoria y pueda justificarse ahora lo que entonces no se explicó. La consecuencia sería, por tanto, mantener intacto el procedimiento de elaboración del plan, conservando sus trámites, que resultarán inmunes a la nulidad por obra y gracia de esa actuación complementaria, y retroactiva, de subsanación.

Eso fue exactamente lo que hizo el Ayuntamiento de Madrid tras la Sentencia del Tribunal Superior de Justicia de Madrid de 27 de febrero de 2003 que anuló el Plan General de 1997: aprobar, en ejecución de sentencia, un detallado complemento de la Memoria inicial del Plan que justificaba con todo lujo de detalles el cambio de clasificación del suelo.

20 De las anteriores da cuenta la propia Sentencia de 28 de septiembre de 2012; entre las posteriores pueden verse las de 1 de marzo, 26 de septiembre y 13 de diciembre de 2013, 8 y 14 de octubre de 2014, etc. Véase la reciente Sentencia de 25 de abril de 2016, que hace una minuciosa recopilación de la jurisprudencia anterior a ella. 
El propio Tribunal sentenciador consideró razonable la medida en su Auto de 10 de enero de 2011 por entender que, si bien:

[...] es cierto que nos encontramos ante una disposición de carácter general de naturaleza reglamentaria... lo que, en una lectura rápida, llevaría a la inaplicabilidad del art. 67 de la Ley 30/92 en cuanto no estamos hablando de actos, no es menos cierto que no todo vicio determina la plena nulidad de la disposición, por ejemplo, resultaría desproporcionado asimilar las consecuencias de un vicio manifiesto de incompetencia con la omisión de un informe con infracción del art. 43.f) de la Ley 9/2001, del Suelo de la Comunidad de Madrid, lo que nos llevaría a plantear la solución adoptada por la Administración sobre la base de la aplicación analógica del artículo 66 del mismo texto, esto es la conservación de aquellos actos no viciados.

La Sentencia del Tribunal Supremo de 28 de septiembre de 2012 adoptó, sin embargo, una actitud inflexible:

[...] la aprobación posterior, en ejecución de sentencia, de una justificación que pretende paliar esa ausencia de explicación en el procedimiento de elaboración de la disposición general no puede considerarse que cumple y ejecuta la sentencia que declara la nulidad de una parte del plan general. Así es, no se puede subsanar, enmendar o convalidar el plan nulo. Tampoco pueden conservarse los acuerdos de aprobación definitiva y otros que se mantienen como si las determinaciones del plan no hubieran sido declaradas nulas de pleno derecho. Y, en fin, no podemos considerar que ese posterior complemento de la justificación para la reclasificación de los terrenos pueda tener un alcance retroactivo para intercalarse en el lugar, dentro del procedimiento administrativo, en el que debió haberse producido (fundamento jurídico sexto). [...]

Los efectos propios de la nulidad plena impiden igualmente que el ordenamiento derivado, planes parciales de sectorización, puedan tener cobertura en las concretas normas declaradas nulas, como venimos señalando de modo profuso y uniforme en el ámbito urbanístico. En efecto, la nulidad de pleno derecho de la norma de cobertura, es decir, de la norma que es presupuesto necesario de las normas sucesivas derivadas de la misma acarrea la invalidez de éstas, al tratarse de una nulidad ab initio.

La solución contraria a la expuesta... pretende hacer tabla rasa sobre las diferencias entre la nulidad plena y la mera anulabilidad.

La tesis que la Sentencia del Tribunal Supremo hace suya está, como es obvio, en todos los Manuales de Derecho Administrativo y resulta, ciertamente, de preceptos bien conocidos de las Leyes de Procedimiento Administrativo que se han ido sucediendo, pero su aplicación cuando, como ocurre en este caso, 
supone la descalificación a radice de quince años de historia, de vida, debe conjugarse con la de otros preceptos legales que la moderan, porque el derecho, que es más que un conjunto de normas aisladas unas de otras, es para la vida y no al revés ${ }^{21}$, esto es, para encajar esta a martillazos en las categorías conceptuales elaboradas por los juristas. Dos ejemplos bastan para ilustrar la idea, que es obvia, por lo demás. Los contratos suscritos por la Administración sin contar con crédito presupuestario bastante son nulos de pleno derecho, como establece hoy el art. 32.c) del vigente Texto Refundido de la Ley de Contratos del Sector Público y antes lo hacían las leyes precedentes, lo que, obviamente, no impedía ni impide pagar al contratista la obra efectivamente realizada para evitar el enriquecimiento injusto que en otro caso se produciría a favor de la Administración ${ }^{22}$. Los actos nulos sí pueden producir efectos en algunos casos.

El art. 110 de la vigente Ley de Procedimiento Administrativo Común de 1 de octubre de 2015 recoge hoy, como es notorio, los límites a la revisión de oficio de los actos administrativos, es decir a la declaración de la nulidad de pleno derecho, que no sana ni se convalida con el paso del tiempo según sabemos, pese a lo cual no puede acordarse «cuando por prescripción de acciones, por el tiempo transcurrido o por otras circunstancias... resulte contrario a la equidad, a la buena fe, al derecho de los particulares o a las leyes».

El lenguaje común explica muy bien esta idea sin necesidad de darla más vueltas: muchas veces es peor el remedio que la enfermedad. Una enfermedad leve, la falta de una explicación suficiente del cambio de clasificación de unos terrenos, que podría haber curado en unas pocas semanas, nos ha tenido postrados quince largos años. No tiene sentido, desde ningún punto de vista.

\section{RECTIFICACIONES NECESARIAS DE LA JURISPRUDENCIA AL USO}

De lo hasta aquí dicho resulta con claridad que es necesario reflexionar nuevamente sobre un tema, la teoría de las nulidades, que creíamos tener ya aprobado con nota desde hace mucho tiempo. No es así, como ha podido comprobarse.

Los trámites procedimentales tienen, desde luego, una muy especial importancia cuando estamos en presencia de una potestad discrecional, ya que

21 «La vida no está al servicio del Derecho, sino al revés», dice literalmente la Sentencia del Tribunal Superior de Justicia de Madrid de 6 de octubre de 1989 (ponente: L. M. López Mora), que me gusta recordar siempre que tengo ocasión.

22 Sobre el enriquecimiento injusto me remito al estudio de L. Cosculluela (1977), "Consideraciones sobre el enriquecimiento injusto en el Derecho Administrativo", Revista de Administración Pública, 84. 
es, por hipótesis, muy difícil ejercer algún control sobre la resolución que ponga fin al procedimiento. Pero, aun así, carece de justificación cualquier intento de sustantivar las cuestiones de forma, que son y serán siempre de carácter instrumental, servicial. Esa es su naturaleza.

Su valoración no puede prescindir de la idea de lo que realmente aportan a esa resolución final a la que institucionalmente se orientan o, si se prefiere decir así, de lo que realmente privan los vicios o defectos que puedan cometerse en el curso del procedimiento.

A quien alega esos vicios hay que pedirle, por lo pronto, como requisito de seriedad de su denuncia, que diga con claridad en qué medida ha podido afectar este a la posición jurídica que defiende y en qué y por qué ha podido influir negativamente en la decisión que recurre, porque nadie tiene derecho a la anulación de una decisión por infracciones que no le afectan ${ }^{23}$. Esto es tanto más necesario cuanto más compleja es dicha decisión y lo es en grado máximo cuando el objeto de la misma es la aprobación de un plan urbanístico, ya sea de ordenación territorial o de ordenación urbana, porque en estos casos y de modo especial en el último de ellos hay miles, docenas de miles de determinaciones muy diferentes entre sí, que se proyectan sobre puntos muy distintos y muy alejados unos de otros dentro de un territorio muy extenso.

Esa exigencia de concreción es muy importante, además, porque la valoración del vicio o defecto denunciado no puede ser nunca el resultado puro y simple de la aplicación mecánica de una norma legal, que se limita por su generalidad a indicar la dirección que hay que seguir, pero que no impone en absoluto hasta dónde hay que llegar en todo caso. La valoración tiene que hacerse siempre a la vista de las circunstancias del caso $^{24}$. El informe de la Autoridad Portuaria, por ejemplo, es muy importante, sin duda, imprescindible sencillamente, en todo lo que concierne al puerto y a su zona de servicio $\mathrm{y}$, en ciertos casos, también en lo que indirectamente puede afectar a aquel o a esta, como, por ejemplo, el trazado de las vías de acceso al puerto o cosas semejantes, pero carece totalmente de transcendencia en relación a la clasificación o calificación urbanística de unos terrenos situados al otro extremo de la ciudad. ¿Por qué considerar entonces que la omisión de ese informe es determinante de la nulidad absoluta de todo el Plan de Ordenación con el inmenso trastorno que esa anulación supone para toda la ciudad?

No pretendo inventar nada. Recordaré solamente una importante Sentencia de 13 de febrero de 1992, de la que fue ponente el Sr. Delgado Barrio,

23 Véase J. García Luengo (2016: 103).

24 Sobre la necesidad de un análisis casuístico de las situaciones provocadas por la infracción formal, véase ibid.: 111. 
en la que a propósito de la falta de justificación de la ordenación de unos terrenos del recurrente en las aprobaciones, provisional y definitiva, de unas normas subsidiarias, se dice que esa "falta de motivación deja sin conocer las razones que fundaban la ordenación discutida, sin que se cuente con base para valorar si se ajustaba o no a Derecho», por lo que concluye afirmando que «procedente será una anulación de actuaciones con referencia estricta al terreno litigioso a fin de que con la necesaria motivación se establezca la ordenación adecuada a las exigencias del interés público». ¿Por qué más?

¿Quid en el caso, más problemático en apariencia, de la falta de respuesta a las alegaciones formuladas en el trámite de información pública? La Sentencia de 22 de septiembre de 2015 a la que más atrás he hecho referencia a propósito de la ausencia del informe de impacto de género anuló el Plan de Ordenación territorial de la Costa del Sol Occidental en primer término por esa razón, esto es, porque «en el primer periodo de información pública abierto por la Administración autonómica... la entidad mercantil recurrente formuló una serie de alegaciones que no merecieron la respuesta de la Administración... ya que se limitó a contestar las alegaciones que se presentaron en el segundo periodo de información pública».

¿Puede decirse en estas circunstancias que se produjo una efectiva indefensión del recurrente? ¿Puede decirse realmente que no fue oído en el procedimiento, que es lo que intenta asegurar la equiparación de la falta de respuesta a las alegaciones formuladas en la información pública a la privación del derecho de audiencia que hace la jurisprudencia que la Sentencia cita? Es evidente que no.

Estoy totalmente de acuerdo en que las alegaciones deben ser respondidas para que pueda entenderse cumplido el trámite de información pública, destinado a posibilitar la participación ciudadana en la elaboración del procedimiento, pero, aun siendo esto así, ¿es sensato anular en su totalidad un Plan que comprende, ni más ni menos, que toda la Costa del Sol Occidental porque no se respondió a uno de los alegantes en la primera información pública, aunque sí en la segunda? Yo creo sinceramente que no y mucho menos sin intentar valorar siquiera si la alegación tenía o no algún fundamento. No parece que lo tuviera en este caso, además, porque lo que el alegante y luego recurrente pretendía era que la zona adyacente a las Dunas de Artola, calificada por el Plan como espacio libre, volviera a ostentar «la condición de suelo urbanizable programado que tenían antes de la entrada en vigor del instrumento territorial impugnado en la instancia» (sic en el antecedente de hecho séptimo, in fine, de la Sentencia), lo que no era posible, en ningún caso, ya que las Dunas de Artola fueron declaradas Monumento Natural de Andalucía por Decreto del Gobierno andaluz 250/2003, de 9 de septiembre, declaración que conlleva la sujeción, no solo de las Dunas, sino también de los terrenos adyacentes a las 
mismas a un régimen de protección, de acuerdo con lo dispuesto en el art. 27 de la Ley andaluza 2/1989, de 18 de julio. Esa sujeción a un régimen de protección de la zona adyacente a las Dunas de Artola obligaba a clasificar los terrenos como suelo no urbanizable, dados los términos del art. 9.1 $1^{\text {a }}$ de la Ley estatal de Régimen de Suelo y Valoraciones de 13 de abril de 1998, entonces vigente. La alegación no tenía, pues, ningún fundamento.

Hay que mirar siempre lo que hay detrás del vicio de forma o de procedimiento alegado para no llegar al absurdo de anular en su totalidad un Plan de Ordenación - y todo lo que de él traiga causa - al cabo de nueve años de pleitos sin ninguna razón material o de fondo, ya que el Plan en cuestión no podía hacer otra cosa que lo que hizo.

En cualquier caso, aunque no hubiese sido así, la falta de respuesta a la alegación formulada sobre la calificación de la zona adyacente a las Dunas de Artola, que es solo un lugar, un pequeño lugar, de la Costa del Sol Occidental, no tenía por qué determinar la nulidad de pleno derecho de todo el Plan. Ninguna razón, que a mí se me alcance al menos, puede justificar tamaña desmesura.

$\mathrm{Ni}$ siquiera ese «carácter sustancial que tienen las reglas de procedimiento para la elaboración y aprobación de las disposiciones de carácter general» al que la Sentencia de 22 de septiembre de 2015 apela (fundamento jurídico tercero, in fine), porque, antes de llegar a la declaración de nulidad que sería el corolario de ese carácter sustancial, habría que comprobar primero si el vicio denunciado es consistente o no. Porque, si no lo es, llegar a esos extremos supone atribuir a esas reglas un carácter, más que sustancial, sagrado, y eso, francamente, es demasiado.

Hay razones, me parece, serias razones, que aconsejan reajustar la jurisprudencia a la que la Sala Tercera del Tribunal Supremo ha llegado en estos últimos años, yo diría sin querer, deslizándose al impulso de un afán, muy elogiable sin duda, de poner orden, de asegurar la disciplina en la elaboración del planeamiento. El resultado de ese impulso no ha sido positivo. Se ha ido demasiado lejos, tanto que como el procedimiento de elaboración de los planes se ha hecho cada vez más complejo al involucrarse en el mismo los problemas ambientales y estratégicos es difícil, muy difícil, que un plan salga limpio del horno, prácticamente imposible si a esa complejidad de las normas reguladoras se une la hipervaloración de las formas y la absoluta ausencia de matizaciones en función de las circunstancias del caso en las que ha caído la jurisprudencia al uso.

La aplicación automática de la nulidad del pleno derecho a todo el Plan General de ordenación y a todo lo que venga después de él, tenga o no tenga que ver con el vicio o defecto procedimental, en muchos casos banal, que hubiere determinado la declaración de nulidad, debe ser reconducida también a 
sus justos límites. Razones que así lo exijan no faltan, como ya destaqué más atrás.

Se necesita para ello, eso sí, un cambio de la mentalidad tradicional de los jueces, un tránsito desde la actitud propia de meros censores, ahora radicales, que se desentienden pura y simplemente del resultado de su censura por considerar que no es cosa suya, en una aplicación ciega del flat iustitia et pereat mundus a la de colaboradores en una tarea común de regularización de lo que razonablemente pueda considerarse subsanable, de limitación de la contaminación de los actos posteriores al declarado nulo y de las subsiguientes nulidades en cadena e, incluso, de guía capaz de evitar ulteriores tropiezos ${ }^{25}$. En el país vecino lo han hecho así, tras una reflexión colectiva profunda, y parece que con éxito. No hay razón para que nosotros no hagamos algo parecido tras la correspondiente reflexión sobre nuestra propia realidad, que no es muy diferente.

\section{REFORMAS LEGALES QUE SERÍA CONVENIENTE INTRODUCIR EN EL PROCESO CONTENCIOSO DEL URBANISMO}

Los ajustes jurisprudenciales que sugiero aliviarían no poco la situación actual, pero no serían suficientes, como es lógico, para resolver todos los problemas. Habría, pues, que introducir también algunos retoques en la regulación actual del proceso contencioso-administrativo. ¿Cuáles?

En mi primer trabajo sobre este asunto ${ }^{26}$ enuncié ya una serie de ellos, por lo que ahora me limitaré a recordarlos y me detendré solamente en lo que se refiere a la instrumentación de esa idea de la regularización que me parece lo más importante del conjunto y sobre la que pasé entonces muy por encima.

Mi experiencia, ya larga, me lleva a la profunda convicción de que la acción pública en materia de urbanismo no solo no ha aportado nada positivo, sino que ha contribuido a normalizar la corrupción, porque ha propiciado la aparición de personas que han hecho de ella una profesión. Aunque solo fuera por esto, habría que prescindir ya de la acción pública, que, además, carece hoy de la justificación que en 1956 pudo tener. En la actualidad la legitimización para promover un proceso contencioso-administrativo es muy amplia, porque basta con exhibir un interés un punto, solo un punto, superior al que cualquier ciudadano puede tener al respeto y la observancia de la legalidad. La Ley de la Jurisdicción se la reconoce ya sin dificultad no solo a las corporaciones, asociaciones y sindicatos, sino también a los grupos de afectados y uniones

25 Véase H. Delesalle (2016: 1769).

26 Véase el trabajo citado en la nota 2. 
sin personalidad (arts. 18 y 19.1.b). La Ley de Bases del Régimen Local de 2 de abril de 1985 se la reconoce también, por su parte, a los miembros de las corporaciones locales que hubieran votado en contra de los acuerdos correspondientes (art. 63.1.b). Tenemos, además, una Fiscalía Anticorrupción. ¿Para qué queremos más? ¿Para dar vía libre a recursos «crapulosos»?

Me parece bien igualmente la iniciativa francesa de admitir en el propio proceso contencioso-administrativo la posibilidad de reconvención para que el demandado, que se ve obligado a soportar un recurso abusivo, pueda reclamar la condena del demandante al pago de una indemnización por los daños y perjuicios resultantes. Según parece, los resultados de esta iniciativa no han sido muy brillantes hasta ahora, pero, si la Ley de la Jurisdicción incorporara una previsión en este sentido, serviría al menos como un aviso a navegantes, a esos recurrentes abusivos que, aunque se suprimiera la acción pública, seguirían existiendo, como la experiencia francesa demuestra.

Creo también que es muy serio el ejemplo francés de limitar la demolición de construcciones realizadas al amparo de una licencia declarada nula (no de las construidas sin licencia, que deberían demolerse en todo caso, salvo que sea posible su legalización) a las levantadas en zonas sensibles (espacios naturales protegidos, servidumbre de protección, sectores incluidos en planes de prevención de riesgos, servidumbres relativas a los suelos contaminados, zonas de protección de acuíferos, entorno de los bienes de interés cultural, etc). La situación actual en materia de ejecución de sentencias de demolición es insostenible porque pone al sistema entero en una situación límite, ya que o bien se mira para otro lado y se acepta de un modo u otro que una sentencia firme quede inejecutada o bien se afronta deliberadamente la aparición en muchos casos de un auténtico problema social ${ }^{27}$. Si malo es lo uno, peor es lo otro. El ejemplo de Cantabria debería ser suficiente ${ }^{28}$.

Insisto por ello en la conveniencia de recuperar el viejo art. 228 de la Ley del Suelo de 1956, que el Tribunal Constitucional consideró conforme

27 Para evitarlo, la reciente reforma de nuestra Ley jurisdiccional realizada por la disposición final 3.4 de la Ley Orgánica 7/2015, de 21 de julio, ha añadido al art. 108 de aquella un párrafo 3 que permite al juez o tribunal exigir, "como condición previa a la demolición, y salvo que una situación de peligro inminente lo impidiera, la prestación de garantías suficientes para responder del pago de las indemnizaciones debidas a terceros de buena fé», solución claramente inspirada en la Ley de Cantabria que la Sentencia constitucional 92/2013, de 22 de abril, no tuvo más remedio que anular por razones competenciales.

28 Sobre esto me remito al detallado estudio de L. Martín Rebollo (2013), «Ejecución de sentencias de derribo y técnicas obstruccionistas (A propósito de la STC 92/2013)», Revista de Urbanismo y Edificación, 28. 
a la Norma Fundamental ${ }^{29}$, precepto que permitía al Tribunal sentenciador dirigirse a la Administración para que en el plazo de dos meses le notificara «si, por motivos de interés público, se impone seguir o conservar la obra». Si se optase por esto último, el Tribunal fijaría la indemnización que el condenado habría de abonar al perjudicado por los daños y perjuicios que hubiese podido causarle y a la Administración por los inferidos a los intereses generales. Esa indemnización debería servir en todo caso para confiscar el beneficio ilícitamente obtenido por el titular de la licencia anulada.

Una solución de este tipo permitiría situar el problema en el terreno de lo razonable, porque preservaría lo fundamental, ya que la demolición no se eludiría en el caso de construcciones en las zonas sensibles más atrás indicadas, y aseguraría en todo caso la ejecución por equivalente, lo que también es constitucional, de todas las sentencias, evitando las soluciones vergonzantes a las que el maximalismo actual nos empuja a diario.

Vamos ahora con la regularización y con ese papel más activo que en Francia se ha atribuido al juez en el contencioso del urbanismo.

Pues bien, lo primero que hay que subrayar al respecto es que esa nueva posición del juez no sería una novedad radical entre nosotros. El art. 43.2 de la vieja Ley de la Jurisdicción de 1956 ya le permitía, como es bien sabido, salir de su tradicional pasividad cuando «al dictar sentencia, estimase que la cuestión sometida a su conocimiento pudiera no haber sido apreciada debidamente por las partes, por existir en apariencia otros motivos susceptibles de fundar el recurso o la oposición», autorizándole en tales casos a advertírselo así a las partes para que estas pudieran formular las alegaciones que estimaran convenientes al respecto.

Yo he visto hacerlo en contadísimas ocasiones, pero el precepto sigue en pie en el art. 33.2 de la Ley vigente. Es más, el art. 65.2 de esta ha querido, incluso, adelantar esa posibilidad al momento de la vista o de las conclusiones, lo que sin duda es preferible.

Un paso más en esta misma dirección lo ofrece el art. 77 de la propia Ley, según el cual en los procesos en primera o única instancia el juez, de oficio o a solicitud de parte, podrá, una vez formulada la demanda y la contestación, someter a la consideración de las partes «el reconocimiento de hechos o documentos, así como la posibilidad de alcanzar el acuerdo que ponga fin a la controversia».

29 En su Sentencia 67/1984, de 7 de junio, en la que afirmó que «tan constitucional es una ejecución en la que se cumple el principio de identidad total entre lo ejecutado y lo establecido en el fallo como una ejecución en la que, por razones atendibles, la condena es sustituida por su equivalente pecuniario o por otro tipo de prestación». 
El precepto da al juez el protagonismo que la doctrina francesa celebra al permitirle tomar la iniciativa y sugerir a las partes la posibilidad de llegar a un acuerdo, pero lo limita a las «materias susceptibles de transacción" y a las cuestiones que versen sobre «estimación de cantidad».

Todo requiere, ciertamente, un principio y es razonable que para abrir camino se elija el terreno más llano, que es, sin duda, el que el art. 77 de la Ley ha escogido. Nada impide, sin embargo, la extensión de la fórmula a las licencias de construcción, ya que estas son, como es notorio, actos reglados. La apertura por el juez de un trámite de diálogo entre las partes podría hacer ver a estas la posibilidad de enderezar el conflicto, bien corrigiendo los eventuales excesos en que pudiera haber incurrido la licencia recurrida, bien cambiando la disposición de los elementos del proyecto que hubieren resultado conflictivos, bien introduciendo cualesquiera otros ajustes, dentro, por supuesto, de la legalidad aplicable, lo que podría plasmarse mediante la expedición de una nueva licencia modificada que pondría fin al proceso por satisfacción extraprocesal.

No sería difícil, ni mucho menos, afinar esta idea y corregir en lo procedente la redacción actual del art. 77 prolongando así la línea lógica a la que este responde.

Tampoco sería complicado reseńar un precepto nuevo que autorizara al juez para que, una vez que conozca los términos en los que está planteada la impugnación de un plan de ordenación urbana (o de un instrumento de gestión, un proyecto de reparcelación, por ejemplo), esto es, una vez presentados los escritos de demanda y contestación, y que haya podido comprobar, por lo tanto, la ausencia de algún informe preceptivo o la existencia de cualquier otro defecto formal subsanable (la falta de una segunda información pública, que es causa de la caída de tantos planes, o la ausencia de respuesta a las alegaciones que se hubieren presentado en el curso del procedimiento o cualquier otro semejante), pueda dirigirse a la Administración advirtiéndoselo así y otorgándole un plazo prudencial para aportar el informa omitido o para subsanar el defecto apreciado, así como para introducir eventualmente en el plan objeto del debate las correcciones que pudiesen requerir los nuevos elementos obtenidos, de todo lo cual habría de darse, como es natural, traslado a las partes para que pudiesen formular las alegaciones que considerasen pertinentes.

Todo ello permitiría solventar a los pocos meses de la interposición de un recurso defectos de índole procedimental que hoy conducen a la declaración de nulidad de pleno derecho de muchos planes de ordenación, sobre todo generales, con la secuela de problemas que generan tales declaraciones, habida cuenta de que los planes en cuestión han estado en vigor y producido efectos durante los años que tarda en ganar firmeza la sentencia anulatoria de los mismos, que son muchos, como bien nos consta. 
No creo que sea necesario mucho más, pero sí considero que sería muy útil introducir cuanto antes las reformas que he intentado justificar. Aliviarían, sin duda, la presión que hoy soporta el contencioso urbanístico, cuyo panorama actual es absolutamente insatisfactorio.

\section{REFLEXIÓN FINAL}

En las páginas precedentes he pretendido simplemente completar la información que hace cuatro años aporté sobre las propuestas de reforma entonces formuladas en Francia, que hoy son ya derecho positivo, y concretar las reflexiones que al hilo de las mismas expuse sobre nuestra propia realidad, que es muy semejante a la francesa, como ya he dejado dicho, por lo que es muy importante aprovechar la experiencia de nuestros vecinos.

Ello no significa, ni mucho menos, que deje de lado los puntos de vista expuestos desde entonces por otros prestigiosos colegas acerca de la discutible naturaleza jurídica de los planes urbanísticos y de los efectos atribuibles a las eventuales infracciones que pueden viciar el procedimiento de elaboración de los mismos ${ }^{30}$. Sobre el primero de dichos problemas versa específicamente, además, el voto particular de los Sres. J. J. Suay Rincón y M. del Oro-Pulido a la Sentencia de 22 de septiembre de 2015 a la que he hecho referencia más atrás.

Comparto sin reservas estas preocupaciones, que reflejan sin duda un estado de opinión generalizado y creo de la mayor importancia sumarlas a las que yo he expuesto aquí e invitar a reflexionar sobre ellas a esa Sección $3^{\text {a }}$ de la Comisión General de Codificación no hace mucho creada y todavía inédita, que podría ser muy bien quien elevara al Ministro de Justicia un informepropuesta sobre el modo de poner remedio a la situación actual. No puede demorarse ya más tiempo la respuesta a esa plaga insufrible de las anulaciones de los planes de urbanismo que nos descalifica por su zafiedad a todos los juristas españoles.

30 Véase J. A. Santamaría Pastor (20 I 6), «Una imprevista disfunción del sistema urbanístico: la mortalidad judicial de los planes», Práctica Urbanistica, 141, con un valiosísimo anexo sobre los 135 recursos contra planes urbanísticos resueltos por el Tribunal Supremo el año 2014, de los cuales 108 lo fueron en sentido estimatorio, anulando, por lo tanto, los planes impugnados. Véase también J. M. Baño León (2017), «El plan urbanístico en ruina (Un esbozo de reconstrucción)», Práctica Urbanística, 144; y J. M. Baño (2016), «Reconsideración sobre el régimen de impugnación del plan urbanístico", en Gifreu, Bassols y Menéndez (dirs.), El Derecho de la Ciudad y el Territorio, Estudios en Homenaje a Manuel Ballbe Prunes, Madrid: INAP. 